O

\title{
WHAT IF WE COULD CONTROL MICROBIAL COMMUNITIES?
}

\author{
AT HIS LAB AT THE UNIVERSITY OF SOUTHERN CALIFORNIA \\ IN THE US, PROFESSOR JAMES BOEDICKER AND HIS TEAM \\ FOCUS ON UNDERSTANDING THE RULES THAT MAKE \\ COMPLEX NETWORKS OF MICROBES WORK - THE FINDINGS \\ COULD HELP ENSURE MICROBES ARE HELPFUL TO SOCIETY
}

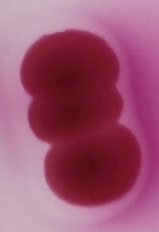




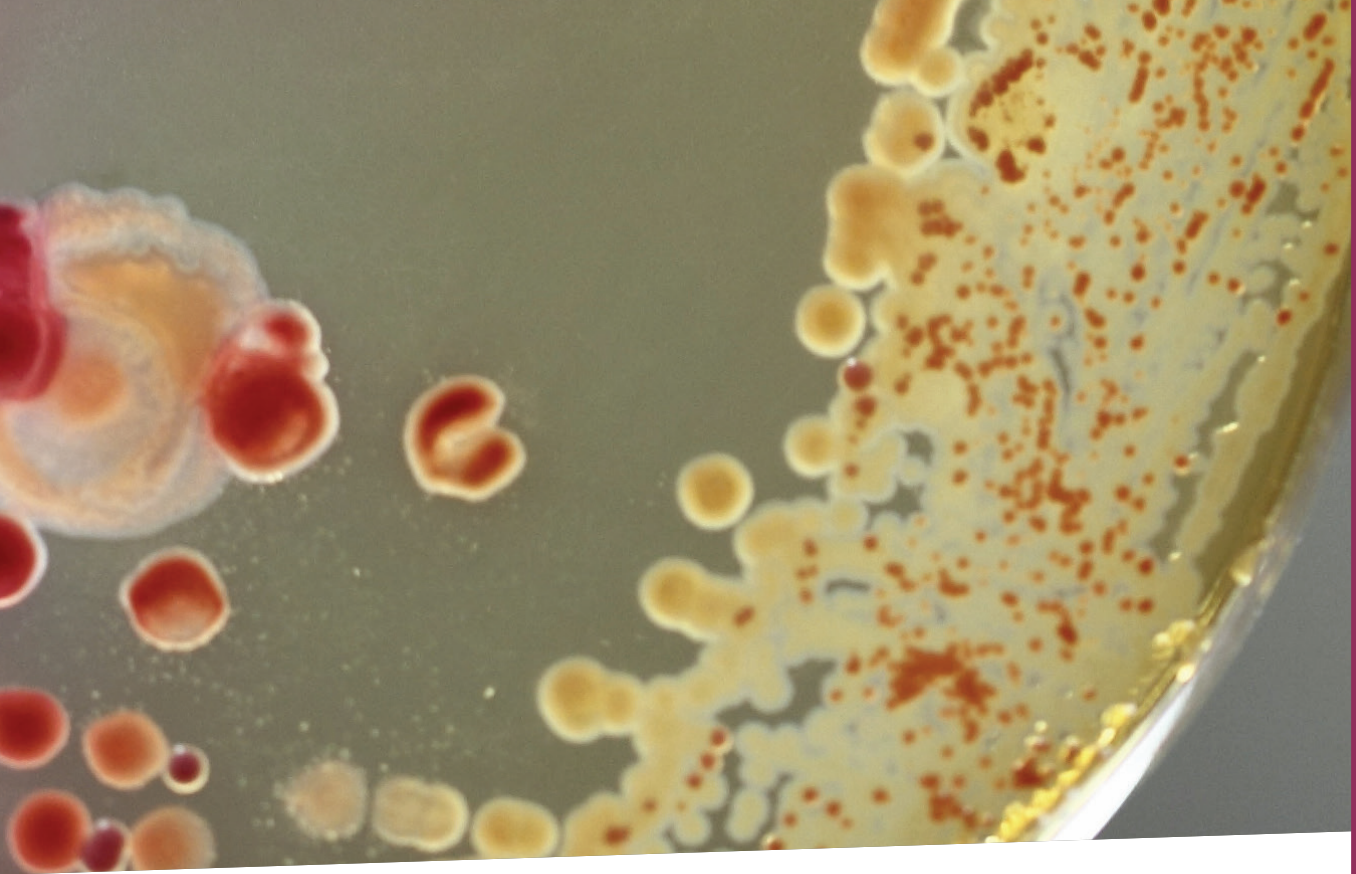

WHAT HAS BEEN LEARNED ABOUT MICROBIAL INTERACTIONS?

Microbes exchange chemical messages to interact and work together - and many species of microbes release special messenger molecules to announce their arrival to neighbouring cells so that they can start working together. Cells have receptor proteins that allow them to detect these messages and respond; without these signal molecules, cells would not know which bacterial species were around or if they were living in a small or large population of cells information that helps cells decide what to do and which proteins to make.

These interactions can have a strong bearing on the overall activity of bacterial ecosystems. "Each species of microbe has many genes that enable the cells to perform a wide variety of different biochemical reactions and display many different behaviours. At any given time, each cell is only performing a fraction of the activities that are possible," explains James. "The interactions between the species, whether it be the exchange of molecular signals or cells sharing the same food source, play a role in the cell turning on and off different activities."

One of the main challenges for James is translating what is learned in the lab to molecular exchange that occurs in real microbial ecosystems in the wild. "In the lab, everything is simplified and controlled, whereas wild ecosystems are complex and unpredictable. It is simply not yet possible to study all the thousands to millions of different microbes in a given location one by one," says James. "Our hope is that by focusing on the general rules by which cells interact and using mathematical models to explore the large-scale consequences of these rules, we can eventually develop a good enough understanding of how interactions between cells influence the overall functions and activities of real communities."

\section{EUREKA MOMENTS}

"One recent success was when we were able to predict how the bacteria Bacillus subtilis was able to interpret complex mixtures of molecular signals. This result proved that even in diverse communities of microbes, it might be possible to predict how individual strains gather multiple pieces of information to determine what to do next," says James. "Another success was finding that multiple different species of bacteria could exchange molecules including DNA through vesicles.

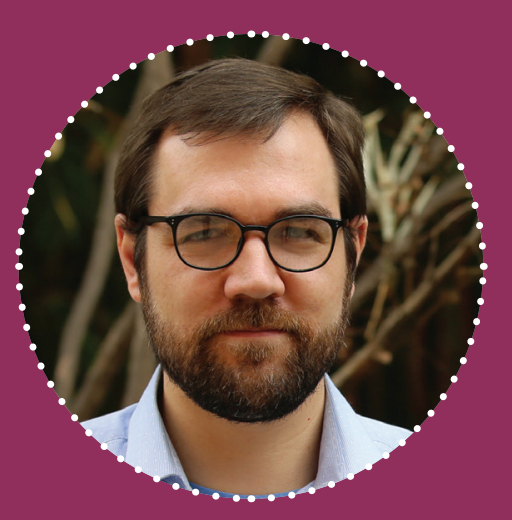

JAMES BOEDICKER

Associate Professor of Physics, Astronomy and the Biological Sciences, USC Dornsife, University of Southern California, USA

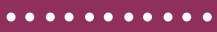

\section{FIELD OF RESEARCH}

Biophysics

\section{RESEARCH PROJECT}

James' research is focused on understanding more about how microbial networks work. His team has developed novel methods to observe microbial networks and is looking at strategies to manipulate microbial communities.

\section{FUNDERS}

National Science Foundation, Office of Naval Research, Army Research Office
This work was supported by the NSF, under awards MCB-1818341 and PHY-1753268. The contents are solely the responsibility of the authors and do not necessarily represent the official views of the

$$
\text { funding agency. }
$$

It was an eye-opening moment that made us realise how important vesicles might be to interactions within microbial ecosystems."

\section{LOOKING AHEAD}

Ultimately, James' work will help identify strategies to manipulate microbial communities in the world beyond the lab - understanding how microbes interpret and respond to complex mixtures of signals will help us control what bacteria are doing. The team's work in vesicle-mediated gene exchange could represent a major breakthrough in biotechnology. Improved treatments of genetic diseases is one possibility, but more generally, demonstrating that vesicles could help a broad range of cells take up DNA would have ramifications across a range of applications. 


\section{. \\ ABOUT BIOPHYSICS}

Given that biophysics is concerned with observing what happens at incredibly small scales, it is hardly surprising that it is a relatively young branch of scientific enquiry. However, theories relating to biophysics were first posited in the 19th century when the Berlin school of physiologists presented several theories. Indeed, Adolf Fick, who was a student of the Berlin school's Carl Ludwig, published the first biophysics textbook in 1856. However, it was not until fairly recently that technology developed to a point where the tools of biophysics could help us understand microbes.

Since then, the field has expanded at a rapid rate and the potential applications of biophysics extend to addressing climate change, improving medicine and combatting food shortages. Given the relative infancy of the field, there is still much to be explored but that should be thought of as exciting rather than hindering - and if you enter the field, you could make significant contributions to the world!
WHAT DOES JAMES FIND REWARDING ABOUT BIOPHYSICS? James is keen to emphasise the puzzle-solving aspect of the field, where progress can be difficult to achieve, but extremely rewarding when it is achieved. "It is a whole community of different people working together, building upon the work of all the great scientists that came before us. The fun of discovering new things and trying to solve problems that haven't been solved yet is the best part," says James. "Of course, I keep in mind that research is important for society at large. There are important issues that we face as a society and we rely on science to make the world a better place in the future. Besides having fun, I do choose problems to work on that I believe will have a positive impact on society."

WHO DO BIOPHYSICISTS

COLLABORATE WITH?

James and his team collaborate with scientists around the world. For example, the team regularly speaks with biologists, computer scientists, mathematicians, engineers, ecologists and physicists. One of the exciting aspects of James' research is that as it opens up into new avenues, different expertise is required, so collaboration is crucial.

WHAT ISSUES WILL FACE THE NEXT GENERATION OF BIOPHYSICISTS?

Given it is a relatively new field, there are so many different directions still to explore. As technology advances, so too do the potential areas to investigate. It is difficult to categorically state what issues the next generation of biophysicists will face, but we can be sure that it will be an area that is essential to tackling problems of the future. For James, the most important thing is to be open to new ideas and remain aware of the advances made in related fields.

\section{EXPLORE A CAREER IN BIOPHYSICS}

- The Biophysical Society is a brilliant website to look through and it has a section dedicated to education and careers that should prove useful to those interested in exploring further: https://www.biophysics.org/

Nature has resources dedicated to the study of biophysics, which should give you an idea of the research taking place within the field:

https://www.nature.com/subjects/ biophysics/nature

The average salary for a biophysicist can range between $\$ 97,000$ for biophysics teachers and $\$ 105,000$ for research biophysicists. However, this depends on the specific area of expertise and level of experience.

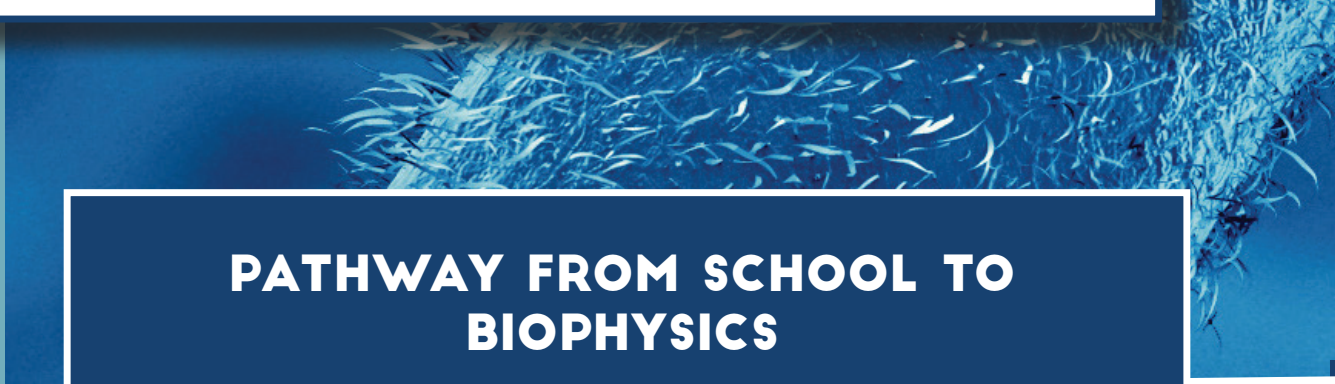

James says that it is possible to approach biophysics from many different backgrounds, so there is no defined pathway. "Going through school myself, I started out as a chemical engineer, then studied chemistry, and then physics and molecular biology. Because biophysics is diverse, you could come from many disciplines including engineering, math or more traditional areas of biology," says James. "However, it is a good idea to take some physics courses. Even the intro classes of Newtonian mechanics and electricity and magnetism that non-physics majors take can give you a sense of the physics mindset."

Undergraduate degrees in biophysics are relatively uncommon, so most aspiring biophysicists start by studying maths, chemistry or physics and supplement these courses with biology modules.

A degree in a relevant subject will be required for postgraduate study.

https://study.com/articles/Careers_in_Biophysics_Job_Options_and_Education_ Requirements.htm 


\section{.}

WHAT WERE YOUR INTERESTS

WHEN YOU WERE YOUNGER?

As a child, I was interested in science, of course, but also classical music, cooking and building forts!

WHO OR WHAT INSPIRED YOU TO BECOME A SCIENTIST?

When I was younger, I liked my science classes in school and watched Mr. Wizard, but I didn't really know any working scientists growing up. Of course, science teachers are a type of scientist, but their job is different to being in the lab and working on an unsolved problem. It wasn't until I went to college and was surrounded by amazing scientists doing all different types of research that I finally realised what it meant to be a research scientist. I can remember being on an airplane, flying home for Thanksgiving during my first semester of college, excited about taking college calculus, and trying to derive the size of the circle traced out by the empty cup on my tray table. It was exciting to use what I was learning in college to actually solve a problem in real life.
Later that year, I emailed someone at my university to ask how to get started doing research and their first question to me was, "What do you want to work on?" - something I hadn't thought about before! I liked chemistry and polymers, so I worked in Paula Hammond's lab on polymer morphology and drug release. From that point, I was hooked and have been working in a research lab ever since.

WHAT ATTRIBUTES HAVE MADE YOU SUCCESSFUL AS A SCIENTIST?

Persistence is key to any scientist because research is typically difficult and requires many repeated attempts. Another one of my strengths is creativity. Being able to see a problem from a different perspective, drawing on different experiences from my past - that is often the key to finding a better path forward. At times, creativity is a trait associated more with artists or musicians, but it is equally important in science.

HOW DO YOU OVERCOME OBSTACLES IN YOUR WORK AND SWITCH OFF OUTSIDE THE LAB?
There are always many obstacles standing in the way of pushing science forward. When I run into one, asking others for advice can help. Sometimes, someone else will see something you are missing. Fortunately, relaxing and switching off comes naturally to me! I rarely think about work when I am home. I enjoy spending time with family and friends, cooking dinner, catching a movie or playing pinball. Then, the next day it is back to thinking about science!

\section{WHAT ARE YOU MOST PROUD OF} SO FAR?

I am proud of many things I have done as a scientist. Becoming a professor and starting my very own research lab was a big day. It gave me the sense that I had really made it and would have the opportunity to continue working on exciting research problems. Also, working with my first few students and seeing them develop as scientists over the years has been a great feeling. For the future, I want to keep plugging away at my research, hopefully helping to make a few big discoveries along the way.

\section{JAMES' TOP TIPS}

OI Follow your passion. It is so important to find what you are interested in learning more about and then pursue it - half the battle will have already been won because it is something that you want to do.

02 If you are considering becoming a scientist, try to find a scientist in your area to talk with or help arrange an opportunity to actually get started doing research. At the same time, keep in mind that everyone starts out without knowing much at first, so don't worry about not having any experience.

03 Try not to fall into the trap of sticking with what you already know or what you have done in the past. Part of the fun is embracing new things!



